\title{
Bone marrow aspiration versus trephine biopsy: diagnostic value of both modalities when done simultaneously.
}

1. MBBS, M.Phil (Hematology) Assistant Professor Hematology Khyber Medical College, Peshawar.

2. MBBS, M.Phil (Histopathology) Demonstrator Pathology Federal Medical and Dental College, Islamabad.

3. BDS, MSPH Demonstrator Bolan Medical College, Quetta.

Correspondence Address: Dr. Asmara Rasheed Department of Pathology Federal Medical \& Dental College asmarasami7@gmail.com

Article received on: 29/09/2020

Accepted for publication: $12 / 02 / 2021$

\section{Muhammad Ihtesham Khan ${ }^{1}$, Asmara Rasheed ${ }^{2}$, Sami Iqbal ${ }^{3}$}

ABSTRACT... Objective: To compare diagnostic value of bone marrow aspiration and bone marrow trephine in reaching to final diagnosis. Study Design: Cross Sectional Descriptive study. Setting: Pathology Department of Khyber Teaching Hospital, Peshawar. Period: December 2015 to September 2016. Material \& Methods: About 199 bone marrow procedure were done during study period. Nine cases were excluded because their trephine biopsy specimen was not available. So, the remaining 190 cases, of both the sexes and age above 2 years were included. Bone marrow aspiration and trephine biopsy were obtained from all the patients, and examined. Qualitative data was determined by frequency and percentages. Quantitative data was shown by mean and standard deviation. Results: 190 cases were included in the study. The mean age of the sample was $40 \pm 11.5$ SD years (range: 2 to 81 years). Bone marrow aspirate alone could diagnose $139(72.8 \%)$ cases while trephine biopsy alone was sufficient to diagnose 12 (6.3\%) cases. Both the modalities showed similar diagnosis in 39 (20.9\%) cases. Conclusion: Leukemias, anemias, and idiopathic thrombocytopenic purpura can be diagnosed by marrow aspiration alone. Aplastic anemia and myelofibrosis need marrow trephine for diagnosis. Both these modalities are important lest any diagnoses should be missed.

Key word: $\quad$ Bone Marrow Aspirate, Marrow Trephine, Myelofibrosis.

Article Citation: Khan MI, Rasheed A, lqbal S. Bone marrow aspiration versus trephine biopsy: diagnostic value of both modalities when done simultaneously. Professional Med J 2021; 28(12):1844-1849. https://doi.org/10.29309/TPMJ/2021.28.12.6114

\section{INTRODUCTION}

Examination of bone marrow samples is an important test to make diagnosis of a wide spectrum of hematological diseases. ${ }^{1-5}$ There are a number of diseases that cannot be diagnosed without doing bone marrow biopsy. ${ }^{6-11}$ It is the first investigation done if patient has unexplained cytopenias or hepatosplenomegaly. 5,11,12

There are two aspects of the marrow examination, i.e. aspiration, and trephine. The aspirate sample helps determine the morphology of cells of each lineage, cell counts, adequacy of megakaryocytes, and detection of iron stores in macrophages. ${ }^{1,3,13-15}$ The trephine is useful for assessing the framework of the bone marrow and determination of pattern of infiltration of the marrow by atypical or metastatic mononuclear cells, in addition to cellularity. ${ }^{1,3,13-15}$ Both are diagnostically important. ${ }^{15}$ When both are done together, they complement each other, and thus guide the hematologist to a particular diagnosis with more accuracy. ${ }^{2,16}$

In routine practice, both the types of specimens are taken in the same time, and examined simultaneously. ${ }^{2,3,17}$ In certain setups, facilities for processing of the trephine biopsy sample are not available. So, examination of only bone marrow aspirate is done, and patient is advised to do bone marrow trephine biopsy later.

The preparation of marrow trephine slides is time consuming and lengthy procedure. ${ }^{1}$ On the other hand, bone marrow aspiration is a rapid method where slides are simply stained, and no further processing is required. ${ }^{1}$ The hematologist first examines the bone marrow aspirate slides, as it is processed rapidly as compared to trephine samples. ${ }^{1}$ Bone marrow trephine biopsy sample is examined later on when the slides are processed. The findings are then noted and 
diagnosis is made in the light of clinical history of the patient. In most of the cases, the findings of the aspirate and trephine coincide. But in certain cases, the findings may not match and may be discordant, which leads to confusion on part of the hematologist. ${ }^{1}$ In certain cases, bone marrow trephine biopsy alone helps in making final diagnosis. ${ }^{3}$ This is particularly true in conditions where either aspirate is inadequate or gives a dry tap and in cases where bone marrow has undergone fibrosis. ${ }^{3}$ The recent advancements in technology like flow cytometry and molecular analysis have made it easier to make the definitive diagnosis. ${ }^{3}$

A very few studies have compared the utility of bone marrow aspiration and trephine with each other. So, the present study was done to compare the utility of these two modalities. It will help assess whether both the specimens should be obtained from every patient, and we can rely on only one of these in certain cases, thus relieving the patient from unnecessary additional stress.

\section{MATERIAL \& METHODS}

This Cross Sectional Descriptive study was conducted at Khyber Teaching Hospital, Pathology Department from 1-12-2015 to 30-92016. The sampling technique was purposive non probability method. The number of patients was 190.

\section{Inclusion Criteria}

All cases above 2 years of age presenting to Pathology department for bone marrow biopsy were included in the study.

\section{Exclusion Criteria}

Cases where aspirate or trephine samples were not available, or were inadequate to comment on, or cases with diluted (showing no hematopoietic cells) samples were excluded from the study

Both bone marrow aspiration and trephine biopsy were done in all cases. Marrow specimens were taken from posterior superior iliac crest on right side. The area was cleaned with alcohol swab, local anesthetic was given. Aspiration sample was taken. Trephine biopsy was taken in the same sitting. Slides were stained using Wrights stain and Prussian blue stain for detecting iron stores. Slides were examined under microscope, and findings were recorded. The aspirate smears were examined for the cellularity, presence of megakaryocytes, and any abnormal cells. Bone marrow trephine slides were examined for cellularity, fibrosis, presence of fat spaces, megakaryocytes, and presence or absence of atypical cells. The findings of both the modalities were noted and comparison was made.

The data was anonymized and it was conveyed to the ethical board. The ethical approval was obtained for the article from the intuitional ethical review board for the study (226/ADR/KMC.

Qualitative variables were analyzed by percentages and frequency. Quantitative data was analyzed using mean and standard deviation. Pie charts were used to show age distribution in sample. Frequency tables were used to show the frequency of the cases and bar charts were used to show frequency of the categorical data.

\section{RESULT}

About 190 cases were subjected to bone marrow biopsy and aspiration. The age range of study population was 2- 81 years (mean age $40 \pm 11.5$ SD years).

The population was composed of 116 (61\%) males and 74 (39\%) females. So, the ratio of male to female cases was 1.6:1 (Figure-1).

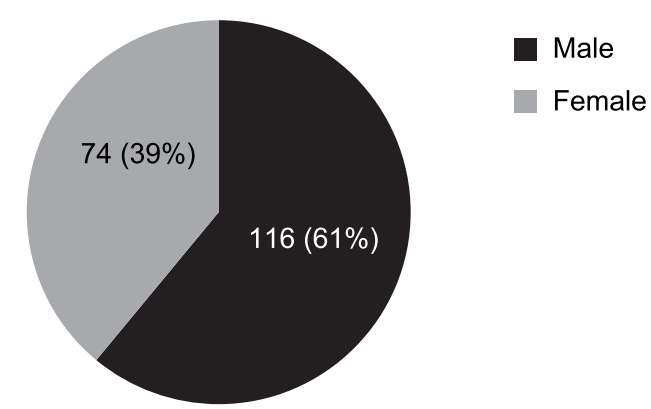

Figure-1. Age distribution of study population.

When comparative analysis of the two modalities was done in different hematological diseases, it 
was found that bone marrow aspirate alone could diagnose cases of leukemia, iron deficiency anemia, and most importantly, hemolytic anemia and megaloblastic anemia (Table-I). Both the modalities were needed to make diagnosis of immune thrombocytopenia purpura, while trephine biopsy alone was needed to make diagnosis of primary myelofibrosis and aplastic anemia (Table-I).

ALL: Acute Lymphoblastic Leukemia. AML: Acute Myelogenous Leukemia. CLL: Chronic Lymphocytic Leukemia. CML: Chronic Myelogenous Leukemia. PVR: Polycythemia vera rubra, PMF: Primary myelofibrosis. ET: Essential thrombocythemia. HES: Hypereisinophilic syndrome. MDS: Myelodysplastic syndrome. IDA: Iron deficiency anemia. ITP: Immune Thrombocytopenic Purpura.

It was analyzed that in 139 (72.8\%) cases, only bone marrow aspirate was sufficient to make diagnosis, while in only $39(20 \% 0$ cases both the modalities were needed to make final diagnosis (Figure-2).

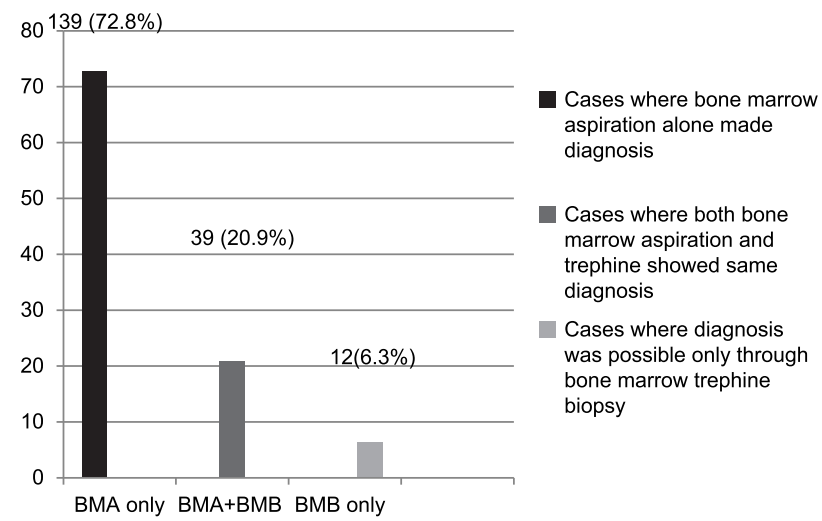

Figure-2. Total number of cases as diagnosed via marrow aspirate and trephine.

\begin{tabular}{|c|c|c|c|}
\hline $\begin{array}{l}\text { Final Diagnosis of cases: } \\
\qquad \mathbf{n}(\%)\end{array}$ & $\begin{array}{c}\text { Cases where marrow } \\
\text { aspirate specimen alone } \\
\text { was sufficient to reach } \\
\text { diagnosis } \\
\text { n (\%) }\end{array}$ & $\begin{array}{c}\text { Cases where Bone } \\
\text { marrow aspiration and } \\
\text { trephine both gave same } \\
\text { findings } \\
\mathbf{n}(\%)\end{array}$ & $\begin{array}{c}\text { Cases where only } \\
\text { marrow trephine } \\
\text { could make } \\
\text { diagnosis. } \\
\mathbf{n}(\%)\end{array}$ \\
\hline ALL: 24(12.6\%) & $19(10 \%)$ & $5(2.6 \%)$ & - \\
\hline AML: 19(10\%) & $17(8.9 \%)$ & $2(1.1 \%)$ & - \\
\hline CML: 7(3.7\%) & $7(3.7 \%)$ & - & - \\
\hline Multiple myeloma: 11(5.8\%) & $8(4.2 \%)$ & $3(1.6 \%)$ & - \\
\hline PVR: 3(1.6\%) & $2(1 \%)$ & $1(0.6 \%)$ & - \\
\hline PMF: 2(1\%) & - & - & $2(1 \%)$ \\
\hline ET:3 (1.6\%) & $2(1 \%)$ & $1(0.6 \%)$ & - \\
\hline HES: 3(1.6\%) & $2(1 \%)$ & $1(0.6 \%)$ & - \\
\hline Anemia of chronic disorder: 10(5.3\%) & $6(3.2 \%)$ & $4(2.1 \%)$ & - \\
\hline Hemolytic anemia: 13(6.8\%) & $12(6.2 \%)$ & $1(0.6 \%)$ & - \\
\hline Aplastic anemia: 12(6.3\%) & - & $2(1 \%)$ & $10(5.3 \%)$ \\
\hline Megaloblastic anemia: 29(15.37\%) & $28(14.7 \%)$ & $1(0.6 \%)$ & - \\
\hline ITP: $10(5.3 \%)$ & $1(0.6 \%)$ & $9(4.7 \%)$ & - \\
\hline
\end{tabular}

Table-I. Comparative analysis of aspirate and trephine in 190 patients of different hematological disorders.

\section{DISCUSSION}

Hematological disorders that cause diffuse involvement of the bone marrow can be diagnosed with the help of bone marrow aspiration alone. ${ }^{1}$ However, in cases where bone marrow is extensively infiltrated, it is sometimes difficult to take the aspirate sample and this results in a dry tap. ${ }^{1}$ In all such cases, trephine biopsy is mandatory for making final diagnosis. ${ }^{1}$

In this study, bone marrow aspiration alone was sufficient to reach the final diagnosis in cases of Megaloblastic anemia, Leukemia, Hemolytic anemia, Multiple myeloma, Anemia of chronic 
disorder, Iron deficiency anemia, Myelodysplastic syndrome and myeloproliferative neoplasms. These hematological disorders produce changes that can be detected on aspirate sample alone if examined with care. On the other hand, cases of Aplastic anemia, mononuclear infiltration and myelofibrosis could not be diagnosed without bone marrow trephine biopsy, as aspirate in these cases was misleading to diagnosis of diluted marrow or hypocellular marrow. In cases of aplastic anemia, aspirate showed scanty cells and lead to diagnosis of diluted marrow in almost all cases. But when trephine was examined, it showed prominent fat spaces and infiltration with lymphocytes, eosinophils, monocytes and plasma cells. These findings are specific to aplastic anemia. ${ }^{6,18}$ In case of myelofibrosis, there is marrow fibrosis. This replaces the normal erythroid and myeloid tissues. ${ }^{6}$ So, aspirate showed hypocellular marrow or dry tap, but trephine biopsy showed fibrosis, thus concluding the diagnosis of myelofibrosis. Similar data is proposed by Gilotra in 2017, where bone marrow aspiration wassufficientto diagnose megaloblastic anemia and iron deficiency anemia. ${ }^{3}$ However, both bone marrow aspirate and trephine were showing similar findings in cases of immune thrombocytopenic purpura and leukemia, cases which were diagnosed only on aspirate in the present study. ${ }^{3}$ Bone marrow trephine biopsy alone helped in the diagnosis of myelofibrosis and aplastic anemia. ${ }^{3}$ Same data is proposed by Pori V in 2018, Sajjan N in 2015, Patro MK in 2018, and Kaur $M$ in 2014. , $2,5,19$ In study done by Humphries, it was found that cases with dry tap on bone marrow aspirate showed myelofibrosis when their trephine biopsies were examined. ${ }^{20}$ Thus, if aspirate gives a dry tap, the hematologist should not assumed that it is because of the faulty procedure, but should prompt the hematologist to examine the trephine biopsy. Thus both bone marrow aspiration and trephine biopsy should be regarded as mandatory to reach final diagnosis.

In the present study, it was seen that about 171 (68\%) cases could be diagnosed on bone marrow aspirate only. In 57 (22.7\%) cases, findings on aspirate and trephine coincided, and in the remaining $23(9.3 \%)$ cases, only bone marrow trephine could diagnosis. So in most of cases, marrow aspirate was sufficient to reach final diagnosis. Nanda A suggested the same findings, in which marrow aspiration alone could diagnose in $88.6 \%$ cases. ${ }^{21}$ In $11.4 \%$ cases, trephine biopsy was necessary for making a diagnosis because marrow aspirate was not giving any direction towards diagnosis. ${ }^{21}$ Myelofibrosis, marrow infiltration and aplastic anemia were among these cases. ${ }^{21}$ These findings are strikingly similar to that reported in the present study.

Most of the hematological disorders can be diagnosed with the help of aspirate alone, but one main limitation of aspirate is mixing of aspirate sample with blood cells, which gives a diluted sample. ${ }^{1,22,23}$ This in turn leads to error in calculating percentage of hematopoietic cells and presents a false picture of the marrow cellularity. ${ }^{1,22,23}$ Bone marrow trephine biopsy gives information about cellularity and architecture of the marrow. ${ }^{1}$ Therefore, examination of trephine sample is more helpful in cases of primary myelofibrosis, aplastic anemia, and in mononuclear infiltration. ${ }^{1}$ Marrow trephine biopsy also allows assessment of pattern of distribution of abnormal mononuclear or metastatic cellular infiltrate, which is not possible in case of aspirate. ${ }^{17}$

Therefore, it both the aspirate and trephine specimens should be examined together, because both the modalities are complementary to each other. Similar recommendations are suggested in literature. $2,5,24,25$ The diagnostic significance of one exceed the other, depending on the nature of underlying hematological disorder.

\section{CONCLUSION}

Cases of aplastic anemia and myelofibrosis necessarily warrant the examination of bone marrow trephine sample in addition to aspirate and blood picture. In the remaining hematological disorders, bone marrow aspirate is sufficient to diagnose cases. Therefore, it is concluded that both marrow aspiration and trephine biopsy increase the diagnostic yield when done together.

\section{RECOMMENDATION}

We recommend that further studies should be 
done including multiple centers to create data that may truly be representative of whole population. We also recommend that bone marrow aspiration and trephine biopsy should be examined together to reach to final diagnosis. Cases with dry tap on aspirate should never be regarded as due to faulty technique and a look should always be given to trephine biopsy specimen in such cases. Copyright@ 12 Feb, 2021.

\section{REFERENCES}

1. Puri V, Sharma P, Kotru M, Sikka M, Sharma S. Utility of simultaneous assessment of bone marrow aspirates and trephine biopsy sections in various haematological disorders. Iraqi J Hematol. 2018; $7(1): 26-32$.

2. Patro MK, Santosh T, Bal AK, Choudhury A, Nayak J, Behera. Correlation of bone marrow aspiration and trephine biopsy in various haematological disorders: A study of 3 years. Annals Path Lab Med. 2018; 5(3); 194-203.

3. Gilotra M, Gupta M, Singh S, Sen R. Comparison of bone marrow aspiration cytology with bone marrow trephine biopsy histopathology: An observational study. J Lab Physicians. 2017; 9(3): 182-9. doi: 10.4103/ JLP.JLP_117_16.

4. Khan Ml, Ahmad N, Fatima SH. Haematological disorders; Analysis of hematological disorders through bone marrow biopsy examination. Professional Med J. 2018; 25(6):828-34.

5. Kaur M, Rana AP, Kapoor S, Puri A. Diagnostic value of bone marrow aspiration and biopsy in routine hematology practice. J Clin Diagn Res. 2014; 8(8):FC13-FC16. doi:10.7860/JCDR/2014/9823.4760.

6. Munir AH, Qayyum S, Gul A, Ashraf Z. Bone marrow aspiration findings in a tertiary care hospital of Peshawar. J Postgrad Med Inst. 2015; 29(4): 297-300.

7. Addo GB, Amoako YA, Bates I. The role of bone marrow aspirate and trephine samples in haematological diagnoses in patients referred to a teaching hospital in Ghana. Ghana Med J. 2013; 47(2):74-8.

8. Padasaini S, Parsad BR, Rauniyar SK, Shrestha R, Gautam K, Pathak R. Interpretation of bone marrow aspiration in hematological disorders. J Pathol Nepal. 2012; 2:309-12.

9. Syed NN, Moiz B, Adil SN, khurshid M. Diagnostic importance of bone marrow examination in nonhematological disorders. J Pak Med Assoc. 2007; 57:123-5.
10. Stiffer S, Babarovic E, Valkovic T, Seili-Bekafigo I, Stemberger C, Nacinovic A. Combined evaluation of bone marrow aspirate and biopsy is superior in the prognosis of multiple myeloma. Diagn Pathol. 2010; 5:30.

11. Khan A, Aqeel M, Khan TA, Munir A. Pattern of hematological diseases in hospitalized paediatric patients based on bone marrow examination. JPMI. 2008; 22 (3); 196-200.

12. Bain BJ. Bone marrow aspiration. J Clin Pathol; 2001; 54:657-63.

13. Patel K, Savjiani N, Gharia B, Falleiro JJ. Comparison of bone marrow aspiration cytology, touch imprint cytology and bone marrow biopsy for bone marrow evaluation. IAIM, 2015; 2(9): 1-10.

14. Bates I, Burthem J. Bone marrow biopsy. In: Bain BJ, Bates I, Laffan MA, Lewis SM, editors. Dacie and Lewis Practical Hematology. 2012; 11th ed. China: Elsevier, Churchill Livingstone; pp. 123-37.

15. Atla BL, Anem V, Dasari A. Prospective study of bone marrow in haematological disorders. Int $\mathrm{J}$ Res Med Sci. 2015; 3:1917-21.

16. Islam A. Bone marrow aspiration prior to bone marrow core biopsy using the same bone marrow biopsy needle. A good or bad practice. J Clin Pathol. 2007; 60:212-15.

17. Garg S, Khushnood M. Comparative analysis between bone marrow aspiration cytology and bone marrow biopsy examination in diagnosis of leukemic patients. Int J Med Sci educ. 2017; 4(1):1-7.

18. Biswajit H, Pratim PP, Kumar ST, Krishna GB, Aditi A. Aplastic anemia a common hematological abnormality. N Am J Med Sci. 2012; 4:384-8.

19. Sajjan N, Mathias M, Shetty J. Comparative evaluation of bone marrow aspiration and bone marrow biopsy in haematological conditions. J Evol Med Den Sci. 2015; 4(102): 16776-8. DOI: 10.14260/jemds/2015/2515.

20. Humphries JE. Dry tap bone marrow aspiration: Clinical significance. Am J Hematol. 1990; 35(4):24750.

21. Nanda $A$, Basu $S$, Marwaha N. BMB as an adjunct to BMA. J Assoc Physicians India; 2002; 50: 893-5.

22. Goyal S, Singh UR, Rusia U. Comparative evaluation of bone marrow aspirate with trephine biopsy in hematological disorders and determination of optimum trephine length in lymphoma infiltration. Mediterr J Hematol Infect Dis. 2014; 6(1):e2014002. doi: 10.4084/ MJHID.2014.002. e Collection 2014. 
23. Toi PC, Varghese RG, Rai R. Comparative evaluation of simultaneous bone marrow aspiration and bone marrow biopsy: An institutional experience. Indian J Hematol Blood Transfus. 2010; 26:41-4.

24. Sudha HM, Krishnappa R, Rishi B. Correlation of bone marrow aspirate, biopsies and touch imprint findings in pancytopenia. J Hematol. 2013; 2(1):8-13.
25. Surbhi G, Usha RS, Usha R. Comparative evaluation of bone marrow aspirate with trephine biopsy in hematological disorders and determination of optimum trephine length in lymphoma infiltration. Mediterr J Hematol Infect Dis. 2014; 6(1): e2014002. DOI: 10.4084/MJHID.2014.00.

\begin{tabular}{|c|l|l|l|}
\hline \multicolumn{3}{|c|}{ AUTHORSHIP AND CONTRIBUTION DECLARATION } \\
\hline No. & \multicolumn{1}{|c|}{ Author(s) Full Name } & Contribution to the paper & Author(s) Signature \\
\hline 1 & Muhammad Intesham Khan & $\begin{array}{l}\text { Principal author. } \\
\text { Data complication, } \\
\text { Analysis, Result, } \\
\text { Complication. } \\
\text { Literature review, } \\
\text { Discussion. }\end{array}$ \\
\hline 3 & Asmara Rasheed & Sami lqbal & \\
\hline
\end{tabular}

